\title{
Tritium-Labeled Compounds V. Radioassay of Both Carbon-14 and Tritium in Films, With a Proportional Counter ${ }^{1}$
}

\author{
Horace S. Isbell, Harriet L. Frush, and Nancy B. Holt
}

(March 28, 1960)

\begin{abstract}
A convenient procedure is described for the radioassay of both carbon-14 and tritium in water-soluble, nonvolatile compounds by means of a windowless, gas-flow, proportional counter. The materials are counted in uniform films of sodium $O$-(carboxymethyl)cellulose that are "infinitely thick" to the radiation of tritium but not to the radiation of carbon-14. Films of uniform thickness are obtained by new techniques which are described in detail.

If only carbon-14 is present, its absolute activity can be calculated conveniently by means of an empirically established curve for the counting-efficiency. If both carbon14 and tritium are present, the films are counted in the proportional counter and are then recounted in the presence of a screen that stops all radiation from tritium but only a portion of that from carbon-14. From a film with a thickness of $0.8 \mathrm{mg} / \mathrm{cm}^{2}$, approximately 43 percent of the radiation of carbon-14 is counted. Of this emerging radiation, approximately 50 percent passes through a screen of 1/4-mil double-aluminized "Mylar." By use of suitable calibration curves for counting-efficiency, carbon-14 and tritium in the same sample can be calculated from the counts with, and without, the screen.

Satisfactory analyses can be made with samples containing less than 0.001 microcurie of carbon-14 and 0.005 microcurie of tritium. The method is suitable for the radioassay of a wide variety of labeled materials.
\end{abstract}

\section{Introduction and Discussion}

Many chemical reactions can be studied by means of double labeling with radioisotopes, as, for instance, with carbon-14 and tritium. However, maximal use of methods employing carbon-14 and tritium has thus far been hampered by the lack of convenient procedures for determining the two radioisotopes in the same sample. Satisfactory analyses of materials containing both carbon-14 and tritium can be made with scintillation counters, but these are expensive and not generally available.

In a previous report from this laboratory, a convenient procedure was described for the radioactivity assay of tritium in water-soluble, nonvolatile compounds by means of a $2 \pi$, windowless, gas-flow, proportional counter [1]. ${ }^{2}$ The sample to be analyzed is contained in a film of sodium $O$-(carboxymethyl)cellulose that is "infinitely thick" to the radiation of tritium. It seemed possible that this method might be so modified that it could be used for the radioassay of carbon-14 and, especially, of carbon-14 and tritium in the same sample. This paper reports such a method. ${ }^{3}$

Radiation from carbon-14 has considerably greater energy than that from tritium. ${ }^{4}$ Consequently, it is

\footnotetext{
${ }^{1}$ Part of a project on the development of methods for the production of radioactive carbohydrates, sponsored by the Division of Research of the Atomic Energy Commission.

${ }_{2}$ Figures in brackets indicate the literature references at the end of this paper. 3 The comparative counting of carbon-14 in films of agar has been reported [2] The described technique differs considerably from that reported here.

4 The maximum range of the radiation from carbon- 14 is about $28 \mathrm{mg} / \mathrm{cm}^{2}$ (see ref. [3] .7 , wheress that from tritium is only about $0.7 \mathrm{mg} / \mathrm{cm}^{2}[4]$. ref. 3$]$ p. 7), whereas that from tritium is only about $0.7 \mathrm{mg} / \mathrm{cm}^{2}[4]$. A film with a thickness of $28 \mathrm{mg} / \mathrm{cm}^{2}$ is difteult to dry to constant weight, and tends to crack and peel. Factors affecti are discussed in ref. [5].
}

impracticable to prepare films that are "infinitely thick" to this radiation. Films that are "infinitely thick" only to the radiation from tritium absorb amounts of that from carbon-14 which are dependent upon film thickness. However, it was found that, by means of an experimentally determined curve for counting-efficiency, absolute determinations of carbon-14 in films of sodium $O$-(carboxymethyl)cellulose (CMC) could be made with high efficiency and good accuracy. ${ }^{5}$

In order to determine carbon-14 and tritium in the same film, advantage was taken of the fact that the radiation from tritium is completely stopped by a screen that permits passage of a considerable fraction of the radiation from carbon-14. By use of experimentally determined counting-efficiences, carbon-14 and tritium can be conveniently determined in the same film from the counts with, and without, a suitable screen.

The radioactivity of tritium-containing materials decreases significantly in the course of several months, and hence a table of the change in activity with time is included for the convenience of the analyst (see table 4, p. 367). This table is based on a half-life value for tritium of $12.26 \mathrm{yr}$ [7].

\section{Materials and Apparatus}

\subsection{Radioactive Materials}

D-Glucose-1-C $C^{14}$ was prepared by the method previously described [8] and was standardized by

5 This procedure for the counting of carbon-14 supplements the more convenient, but less sensitive, formamide counting-method previously developed in this laboratory [6]. 
radioassay of a formamide solution of it in a proportional counter [6]. D-Glucose-1-t [9], was assayed in a proportional counter [10] by comparing its activity in a sulfuric acid-phosphoric anhydride solution with that of the NBS standard tritium oxide sample No. 4926.

\subsection{CMC Stock Solution}

The stock solution used with materials of high specific activity consisted of $1.5 \mathrm{~g}$ of sodium $\mathrm{O}$ (carboxymethyl)cellulose (CMC) ${ }^{6}{ }^{0} 0.5 \mathrm{~g}$ of anhydrous D-glucose, $0.2 \mathrm{~g}$ of phenol, $5 \mathrm{mg}$ of a dye ( $p$-rosaniline hydrochloride), and sufficient water to give $100 \mathrm{ml}$ of solution. The solution was conveniently prepared by mixing the materials with slightly less than the desired amount of water and allowing the mixture to stand for $24 \mathrm{hr}$ or longer. When the CMC had dissolved, the addition of water was completed. The added phenol prevented the growth of bacteria and molds, and the dye revealed the degree of uniformity of the film. In the stock solution used with samples of low specific activity, part or all of the D-glucose, which acts as an organic "ballast" material and plasticizer, was omitted.

\subsection{Equipment for Counting}

Most of the radioactivity measurements were made at $2000 \mathrm{v}$ with a commercial, $2 \pi$, windowless, gas-flow, proportional counter. ${ }^{7}$ The commercial counting gas (consisting of $90 \%$ of argon and $10 \%$ of methane) was dried, before use, by successive passage through soda-lime, anhydrous calcium sulfate, and phosphoric anhydride.

A few measurements of carbon-14 in films were made by means of a commercial "pancake-type" Geiger-Müller tube ${ }^{8}$ in order to confirm the applicability of this equipment to the radioassay of carbon-14 in CMC films.

Stainless-steel, cupped, flat-bottomed, counting planchets, 2 in. in diameter, supplied for use with the proportional counter, were modified by enclosing a $5-\mathrm{cm}^{2}$ area in a shallow, circular groove (cut on a lathe) beyond which the CMC solution did not spread. ${ }^{9}$

The screen used for stopping the radiation of tritium, in the radioassay of tritium and carbon-14, is shown in figure 1. Double-aluminized "Mylar" film, ${ }^{10}{ }_{1 / 4}$-mil in thickness, and having a weight of of $0.9 \mathrm{mg} / \mathrm{cm}^{2}$ was cemented to a circular, aluminum frame that fitted over the top of the planchet. (The thickness of the foil was determined by weighing a sample of known area.) The ability of this foil to stop the radiation from tritium completely was

\footnotetext{
${ }^{6}$ Medium-viscosity product, CMC-12MP, of Hercules Powder Co., Wilmington, Del.

Model PC-3, Nuclear Measurements Corp., Indianapolis, Ind.

No. 1007 T of Anton Electronics Laboratory, Inc., Brooklyn, N.Y.

For the preparation of films, an area on a planchet, circumscribed by a fine groove, is somewhat less convenient than the 2-in., cupped planchet employed groove, is somewhat less convenient than the 2-in., cupped planchet employed
for the counting of tritium only [1]. However, the curved edge of the cupped for the counting of tritium only [1]. However, the curved edge of the cupped
planchet causes a somewhat uneven distribution of the material. Although unimportant in the counting of tritium, this irregularity in distribution is undesirable in films containing carbon-14, which is counted from less than infinite thickness. In the counting of carbon-14 alone, or of carbon-14 and tritium together, the planchets described here should be used.

10 Supplied by Hastings \& Co., Inc., Philadelphia, Pa
}
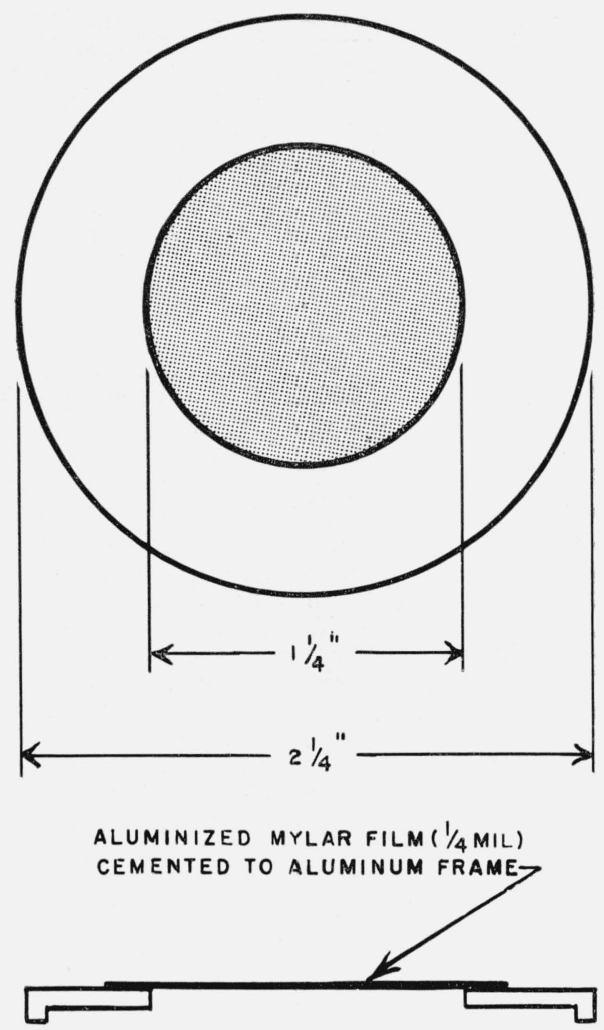

FIGURE 1. Screen for counting carbon-14 in the presence of tritium.

tested by comparing the background count in the absence of radioactive material with that found when the screen shielded a film containing D-glucose- $1-t$. The counts were the same, within the statistical error of measurement.

\subsection{Preparation of Films and Counting of Their Activity}

The planchets were polished by rubbing them, immediately before use, with a dry, 3:1 mixture of infusorial earth and Versene [the tetrasodium salt of (ethylenediamine)tetraacetic acid]; excess cleaning powder was removed by means of a stream of air. ${ }^{11}$ This treatment gives a surface on which the liquids used can spread readily.

For every preparation of the CMC stock solution, the exact weight of the total solids per gram of solution was determined by evaporating weighed quantities of the solution (about $1 \mathrm{~g}^{\circ}$ ), contained in each of several 2-in. planchets, under the conditions used in the analysis. The weight of the residue per gram of the stock solution was used in calculating the weight $(m)$ of total solids in the films made from the stock solution and radioactive materials. A known weight of the sample to be analyzed was dissolved in about $2 \mathrm{ml}$ of the CMC stock solution, and the total weight was determined. ${ }^{12}$ A known weight of

\footnotetext{
11 Rinsing the planchet with water or other solvent impairs the effectiveness of the treatment.

12 Because of the high viscosity of the CMC stock solution, extreme care must be taken to obtain a homogeneous solution with the radioactive material.
} 
this radioactive solution (about $200 \mathrm{mg}$ ) was carefully spread over the inscribed circle of each of several planchets, cleaned as described above. (These weights are most conveniently determined from the weights of a 200-lambda pipet, first, filled with the solution, and then, emptied.) Each planchet was covered with an inverted, 6-in. Petri dish ${ }^{13}$ and allowed to stand at room temperature overnight. The slow evaporation of the solvent left a uniform film, which was heated under an infrared light for $30 \mathrm{~min}$. It was then conditioned by storing it for at least 1 hr in a desiccator over a saturated solution of potassium acetate (in contact with solid potassium acetate). Any planchet in which the edges of the film deviated from the circumscribed area was discarded.

After being conditioned, the films were counted in the windowless, proportional counter operated at $2,000 \mathrm{v}$. The counter was flushed with the counting gas for $30 \mathrm{sec}$ at the start, and for 10 sec between the counting periods. After a preliminary counting period of $1 \mathrm{~min}$, which was disregarded, the activity of the sample was counted, for 3 periods of $100 \mathrm{sec}$ or longer, to give a total count of at least 10,000 . If the counting rates for the several periods changed progressively, the film was reconditioned by storing it for $1 \mathrm{hr}$ or longer over the saturated potassium acetate; it was then re-counted. The counts were corrected for background (determined by counting a film which had been prepared in the usual manner but which contained no added radioactive material).

\subsection{Determination of Counting-Efficiencies}

By means of empirical calibrations of countingefficiencies, it is possible to calculate the absolute activity of carbon-14 from the count given by a film of known weight. Figure 2 and table 1 show experimentally determined relationships between the counting-efficiency for carbon-14 (i.e., cps/dps) and the weight of the film under the various conditions employed in this laboratory. Each point was determined by counting 5 films, of known weight, each containing a known amount of carbon-14. The films were prepared, as described in section 2.4, from

${ }^{13}$ Controlled evaporation is necessary in order to obtain uniform films. When the planchets were allowed to stand in the open air, the films that formed were thicker in the middle than at the edges; and when the planchets were rather closely covered (with small Petri dishes), the films were thicker at the edges than in the middle. In contrast, the films that formed under the 6 -in. Petr dishes were of nearly uniform thickness.

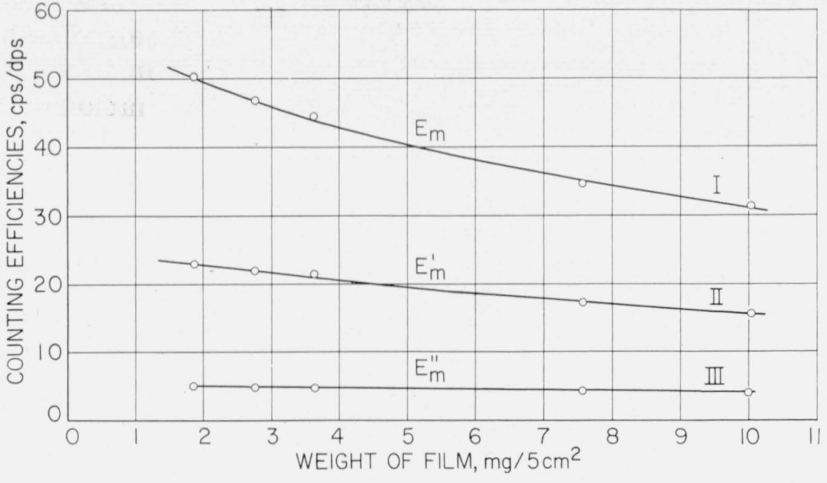

Figure 2. Counting efficiencies for carbon-14 in films.

I. Film without screen.

II. Film covered with aluminized Mylar screen.

III. Film counted with a thin-window, "pancake-type" Geiger-Müller tube.

weighed amounts of a radioactive solution containing known amounts of solids per gram. Each planchet was counted by three different methods. The counting-efficiencies of curve I $\left(E_{m}\right)$ were determined with the windowless, gas-flow, proportional counter; those of curve II $\left(E_{m}^{\prime}\right)$ were determined in the same manner, with the film covered by the Mylar screen of figure 1 ; those of curve III $\left(E_{m}^{\prime \prime}\right)$ were determined with the thin-window, GeigerMüller tube. For routine analyses, a reference table of values of $E_{m}, E_{m}^{\prime}$, and $E_{m} / E_{m}^{\prime}$ was prepared from the curves, for use with films of various thicknesses (see table 2). Having once been determined, the values for counting-efficiencies can be used until a change is made in the equipment or procedure. It is advisable to determine counting-efficiencies by the several methods with the same films. The ratio $E_{m} / E_{m}^{\prime}$ for a given film-thickness is then independent of the absolute activity in the film.

\subsection{Determination of Carbon-14}

The absolute activity of the carbon-14 in a film is given by the equation,

$$
x=\frac{a}{37,000 E_{m}},
$$

where $x$ is the activity in microcuries, $a$ is the observed counts per second (cps), and $E_{m}$ is the appro-

TABLE 1. Counting rates of carbon-14 in CMC films

\begin{tabular}{|c|c|c|c|c|c|c|c|c|c|c|}
\hline \multirow[b]{2}{*}{$\begin{array}{l}\text { Weight of } \\
\text { solution a }\end{array}$} & \multirow{2}{*}{\multicolumn{2}{|c|}{ Activity }} & \multirow[b]{2}{*}{$\begin{array}{l}\text { Weight of } \\
\text { film } \mathrm{b}(m)\end{array}$} & \multicolumn{3}{|c|}{ Count without screen } & \multicolumn{4}{|c|}{ Count with screen } \\
\hline & & & & $\begin{array}{l}\text { Observed } \\
\text { count }{ }^{\circ}(a)\end{array}$ & $\begin{array}{l}\text { Standard } \\
\text { deviation }{ }^{d}\end{array}$ & $\begin{array}{l}\text { Counting } \\
\text { efficiency } \\
\left(E_{m}\right)\end{array}$ & $\begin{array}{l}\text { Observed } \\
\text { count }{ }^{\circ}\left(a^{\prime}\right)\end{array}$ & $\begin{array}{l}\text { Standard } \\
\text { deviation }\end{array}$ & $\begin{array}{l}\text { Counting } \\
\text { efficiency } \\
\left(E_{m}^{\prime}\right)\end{array}$ & $E_{m} / E_{m}^{\prime}$ \\
\hline \begin{tabular}{l}
\multicolumn{1}{c}{$\mathrm{mg}$} \\
100.4 \\
150.6 \\
198.6 \\
$154.4^{\mathrm{e}}$ \\
200.6
\end{tabular} & $\begin{array}{c}\mu c \times 10^{3} \\
3.851 \\
5.777 \\
7.618 \\
5.738 \\
7.454\end{array}$ & $\begin{array}{l}d p s \\
142.5 \\
213.7 \\
281.9 \\
212.3 \\
275.8\end{array}$ & $\begin{array}{l}m g \\
1.84 \\
2.75 \\
3.63 \\
7.57 \\
9.84\end{array}$ & $\begin{array}{r}c p s \\
71.7 \\
99.8 \\
125.2 \\
73.5 \\
85.2\end{array}$ & $\begin{array}{r}\% \\
\pm 2.0 \\
0.7 \\
2.0 \\
1.5 \\
0.9\end{array}$ & $\begin{array}{c}c p s / d p s \\
0.5032 \\
.4670 \\
.4441 \\
.3462 \\
.3089\end{array}$ & $\begin{array}{l}\text { cps } \\
32.2 \\
45.7 \\
58.6 \\
35.7 \\
42.2\end{array}$ & $\begin{array}{r}\% \\
\pm 0.4 \\
.7 \\
.7 \\
.8 \\
.2\end{array}$ & $\begin{array}{c}c p s / d p s \\
0.2259 \\
.2138 \\
.2079 \\
.1682 \\
.1530\end{array}$ & $\begin{array}{l}2.23 \\
2.18 \\
2.14 \\
2.06 \\
2.02\end{array}$ \\
\hline
\end{tabular}

a The radioactive solution was prepared by mixing $200.1 \mathrm{mg}$ of an aqueous solution of D-glucose- 1 - $C^{14}$ having an activity of $0.964 \mu \mathrm{c}$ with sufficient CMC stock solution to give a total weight of $25.130 \mathrm{~g}$. The film from $1 \mathrm{~g}$ of this solution weighed $18.29 \mathrm{mg}$ and contained $0.003836 \mu \mathrm{c}$.

$\mathrm{b}$ Each film had an area of $5 \mathrm{~cm}^{2}$.
- Average of 5 films at each thickness.

d $\sqrt{\Sigma d^{2} /(n-1)}$, where $d^{2}$ is the square of the deviation from the mean and $n$ is the number of films counted. Results expressed as percent of count.

e D-Glucose was added to the radioactive CMC solution. The film from $1 \mathrm{~g}$ of the resulting solution weighed $49.05 \mathrm{mg}$ and contained $0.003716 \mu \mathrm{c}$. 
TABLE 2. Typical counting-efficiencies for carbon-14 in films, under the conditions described ${ }^{\mathrm{a}}$

\begin{tabular}{|c|c|c|c|}
\hline$m$ & $E_{m}$ & $E_{m}^{\prime}$ & $E_{m} / E_{m}^{\prime}$ \\
\hline$m g$ & & & \\
\hline 3.0 & 0.461 & 0.214 & 2. 15 \\
\hline 3.1 & .457 & .213 & 2. 15 \\
\hline 3. 2 & .454 & .212 & 2. 14 \\
\hline 3.3 & .450 & .211 & 2. 13 \\
\hline 3.4 & .447 & .210 & 2. 13 \\
\hline 3.5 & .444 & .209 & 2. 12 \\
\hline 3.6 & .441 & .208 & 2. 12 \\
\hline 3.7 & .438 & .207 & 2. 12 \\
\hline 3.8 & .435 & .206 & 2. 11 \\
\hline 3.9 & .432 & .205 & 2. 11 \\
\hline 4. 0 & .429 & .204 & 2. 10 \\
\hline 4.1 & .426 & .203 & 2. 10 \\
\hline 4. 2 & .424 & .202 & 2. 10 \\
\hline 4. 3 & .421 & .201 & 2. 09 \\
\hline 4.4 & .418 & .200 & 2. 09 \\
\hline 4. 5 & .415 & 199 & 2. 09 \\
\hline 4. 6 & .413 & 198 & 2. 09 \\
\hline 4. 7 & .410 & 197 & 2. 08 \\
\hline 4. 8 & .408 & 196 & 2. 08 \\
\hline 4. 9 & .405 & .195 & 2. 08 \\
\hline 5.0 & .403 & .194 & 2.08 \\
\hline
\end{tabular}

a Table derived from data such as that of table 1 and fig. 2 in the range of film thickness most commonly used for the analysis of carbon-14 and tritium in mixtures.

priate counting-efficiency. If the Geiger-Müller tube is used, the absolute activity of the carbon-14 is likewise calculated from eq (1), but with values for $E_{m}{ }^{\prime \prime}$. There is little difference in the precision of the two methods, but the windowless counter is preferable because it is more sensitive.

\subsection{Determination of Carbon-14 and Tritium in the Same Sample}

In a previous paper, it was shown that the absolute activity of tritium in an "infinitely thick" film may be calculated from the equation,

$$
y=m k a,
$$

where $y$ is the activity in microcuries, $m$ is the weight of the film in milligrams, $a$ is the counts per second measured with the windowless proportional counter, and $k$ is an empirical constant determined with labeled material of known tritium-content. The factor $k$, for use with the $5-\mathrm{cm}^{2}$ area of the planchet, was determined by the method previously reported. With the equipment used in this study, $k=1.94 \times 10^{-4}$ (with a standard deviation of $\pm 1.6 \%$ ). ${ }^{14}$

When both carbon-14 and tritium are present in the

14 Nine films, infinitely thick with respect to the radiation of tritium, and containing $0.01401 \mu \mathrm{c}$ of tritium per milligram of solids, gave an average count of $72.3 \mathrm{cps}$. The standard deviation was $\pm 1.09 \mathrm{cps}$ or \pm 1.6 percent. sample, the films are counted in the windowless, proportional counter and are then re-counted after insertion of the Mylar screen (which entirely stops the radiation from tritium but permits passage of a fraction of that from carbon-14). Carbon-14 is then calculated from the equation,

$$
x=\frac{a^{\prime}}{37,000 E_{m}^{\prime}},
$$

in which $a^{\prime}$ is the observed count with the screen in place, and $E_{m}^{\prime}$ is the appropriate counting-efficiency. The activity of the tritium present is calculated by the following equation, in which allowance is made for the radiation from carbon-14,

$$
y=m k\left[a-a^{\prime} E_{m} / E_{m}^{\prime}\right] .
$$

In order to determine the accuracy of the method, a mixture of carbon-14- and tritium-labeled compounds, each of known radioactivity, was analyzed; the results are summarized in table 3 . The average amounts of carbon-14 and tritium found differed from the known amounts present by 0.70 percent and 1.65 percent, respectively. The results for thin films and for excessively thick films were less satisfactory than those cited in table 3 .

\section{Comments on the Film-Counting Method}

Although the comparative counting of carbon-14 in thin layers has long been an accepted and useful technique, general application of the method has not been satisfactory because of uncertainties regarding the thickness of the sample (see ref. [3], p. 29). Agglomeration or crystallization of materials on the planchet leads to unpredictable variations in the count. The technique described here for the preparation of films has several unique features: (a) The process described for cleaning the planchet produces a surface on which the aqueous solution spreads readily; (b) the use of a thickening agent tends to inhibit crystallization on the planchet; (c) the added coloring matter enables the uniformity of the film to be judged readily; (d) controlled evaporation affords a uniform film; (e) conditioning of the film after drying avoids difficulty (that is otherwise occasionally encountered) with electrostatic charges on the planchet; (f) the presence of "ballast material" in the film makes possible the counting of even

\begin{tabular}{|c|c|c|c|c|c|c|c|c|c|c|c|}
\hline $\begin{array}{l}\text { Weight of } \\
\text { film }(m)\end{array}$ & $\begin{array}{c}\mathrm{C} 14 \\
\text { content }\end{array}$ & $\begin{array}{l}\text { Tritium } \\
\text { content }\end{array}$ & $\begin{array}{l}\text { Count } \\
\text { without } \\
\text { screen } \\
\text { (a) }\end{array}$ & $\begin{array}{l}\text { Count } \\
\text { with } \\
\text { screen } \\
\left(a^{\prime}\right)\end{array}$ & $E_{m}^{\prime} \mathrm{b}$ & $E_{\mathrm{m}} / \mathrm{E}_{m}^{\prime} \mathrm{b}$ & $k \mathbf{c}$ & $\begin{array}{c}\mathrm{C}^{14} \\
\text { found } \mathrm{d}\end{array}$ & $\begin{array}{l}\text { Diff. } \\
\text { from } \\
\text { known }\end{array}$ & $\begin{array}{l}\text { Tritium } \\
\text { found e }\end{array}$ & $\begin{array}{l}\text { Diff. } \\
\text { from } \\
\text { known }\end{array}$ \\
\hline $\begin{array}{c}m g \\
4.50\end{array}$ & $\begin{array}{c}\mu c \times 10^{3} \\
7.16\end{array}$ & $\begin{array}{c}\mu c \times 10^{2} \\
5.47\end{array}$ & $\begin{array}{c}c p s \\
171.0\end{array}$ & $\begin{array}{c}c p s \\
52.3\end{array}$ & 0.199 & 2.09 & 1. $94 \times 10^{-4}$ & $\begin{array}{l}\mu c \times 10^{3} \\
7.10^{\mathrm{f}}\end{array}$ & $\begin{array}{c}\% \\
-0.8\end{array}$ & $\begin{array}{c}\mu c \times 10^{2} \\
5.39 \mathrm{~g}\end{array}$ & $\begin{array}{l}\% \\
-1.5\end{array}$ \\
\hline
\end{tabular}
highly radioactive materials in films of known

TABLE 3. Analysis of a mixture containing known amounts of carbon-14 and tritium a

a Average of results for 7 films.

b Value taken from table 2 .

- See p. 366 and footnote 14 .

d Calculated by eq (3), p. 366 , from $a^{\prime}$ and $E_{m}^{\prime}$.

e Calculated by eq (4), p. 366 , from $m, a, a^{\prime}, E_{m} / E_{\mathrm{m}}^{\prime}$, and $k$.

The standard deviation was \pm 1.7 percent. 
thickness. In the range of thickness from 0.4 to 1 $\mathrm{mg} / \mathrm{cm}^{2}$, good reproducibility and uniformity of the film are readily achieved; whereas, in the extremely thin layers necessary for counting highly radioactive substances alone, uncertainties as to film thickness and uniformity are relatively great. With the equipment used, the film-counting method is adequate for determining less than $0.001 \mu \mathrm{c}$ of carbon- 14 or 0.005 $\mu \mathrm{c}$ of tritium.

Hendler [11] has developed, for carbon-14, a linear relationship between an "absorption correction factor" and the weight of the film. Hendler's relation-

TABLE 4. Decrease of tritium with time a

\begin{tabular}{|c|c|c|c|c|c|}
\hline Time & $\begin{array}{l}\text { Activity } \\
\text { remaining }\end{array}$ & Time & $\begin{array}{l}\text { Activity } \\
\text { remaining }\end{array}$ & Time & $\begin{array}{l}\text { Activity } \\
\text { remaining }\end{array}$ \\
\hline $\begin{array}{c}\text { Days } \\
0 \\
10 \\
20 \\
30 \\
40\end{array}$ & $\begin{array}{c}\% \\
100.0 \\
99.85 \\
99.69 \\
99.54 \\
99.38\end{array}$ & $\begin{array}{l}\text { Days } \\
250 \\
260 \\
270 \\
280 \\
290\end{array}$ & $\begin{array}{c}\% \\
96.20 \\
96.06 \\
95.91 \\
95.76 \\
95.61\end{array}$ & $\begin{array}{l}\text { Days } \\
500 \\
510 \\
520 \\
530 \\
540\end{array}$ & $\begin{array}{c}\% \\
92.55 \\
92.41 \\
92.27 \\
92.13 \\
91.98\end{array}$ \\
\hline $\begin{array}{l}50 \\
60 \\
70 \\
80 \\
90\end{array}$ & $\begin{array}{l}99.23 \\
99.08 \\
98.92 \\
98.77 \\
98.62\end{array}$ & $\begin{array}{l}300 \\
310 \\
320 \\
330 \\
340\end{array}$ & $\begin{array}{l}95.46 \\
95.32 \\
95.17 \\
95.02 \\
94.88\end{array}$ & $\begin{array}{l}550 \\
560 \\
570 \\
580 \\
590\end{array}$ & $\begin{array}{l}91.84 \\
91.70 \\
91.56 \\
91.42 \\
91.27\end{array}$ \\
\hline $\begin{array}{l}100 \\
110 \\
120 \\
130 \\
140\end{array}$ & $\begin{array}{l}98.46 \\
98.31 \\
98.16 \\
98.01 \\
97.86\end{array}$ & $\begin{array}{l}350 \\
360 \\
370 \\
380 \\
390\end{array}$ & $\begin{array}{l}94.73 \\
94.58 \\
94.43 \\
94.29 \\
94.14\end{array}$ & $\begin{array}{l}600 \\
610 \\
620 \\
630 \\
640\end{array}$ & $\begin{array}{l}91.13 \\
90.99 \\
90.85 \\
90.71 \\
90.57\end{array}$ \\
\hline $\begin{array}{l}150 \\
160 \\
170 \\
180 \\
190\end{array}$ & $\begin{array}{l}97.71 \\
97.56 \\
97.40 \\
97.25 \\
97.10\end{array}$ & $\begin{array}{l}400 \\
410 \\
420 \\
430 \\
440\end{array}$ & $\begin{array}{l}94.00 \\
93.85 \\
93.71 \\
93.56 \\
93.42\end{array}$ & $\begin{array}{l}650 \\
660 \\
670 \\
680 \\
690\end{array}$ & $\begin{array}{l}90.43 \\
90.29 \\
90.15 \\
90.01 \\
89.87\end{array}$ \\
\hline $\begin{array}{l}200 \\
210 \\
220 \\
230 \\
240\end{array}$ & $\begin{array}{l}96.95 \\
96.80 \\
96.65 \\
96.50 \\
96.35\end{array}$ & $\begin{array}{l}450 \\
460 \\
470 \\
480 \\
490\end{array}$ & $\begin{array}{l}93.27 \\
93.13 \\
92.98 \\
92.84 \\
92.70\end{array}$ & $\begin{array}{l}700 \\
710 \\
720 \\
730\end{array}$ & $\begin{array}{l}89.73 \\
89.59 \\
89.46 \\
89.32\end{array}$ \\
\hline
\end{tabular}

a Based on a half-life of $12.262 \mathrm{yr}$ [7] and the fundamental decay law: $\ln N / N_{0}=-\lambda t$.

(See for example p. 16 of ref. [12].) ship is useful for correcting counts, observed at one film-weight, to comparable counts at a desired (reference) film-weight; it also provides an excellent means for detecting errors in the measurement of counting-efficiency by means of the deviation from a linear relationship. The data presented here are in accord with Hendler's relationship. However, for routine analyses, the direct use of counting-efficiencies is adequate and convenient.

The authors are grateful to Ruth Ann Peterson for valuable assistance in part of the experimental work reported here.

\section{References}

[1] H. S. Isbell, H. L. Frush, and R. A. Peterson, J. Research NBS 63A, 171 (1959).

[2] C. C. McCready, Nature 181, 1406 (1958). See also, H. Campbell, H. A. Glastonbury, and M. D. Stevenson, Nature 182, 1100 (1958).

[3] M. Calvin, C. Heidelberger, J. C. Reid, B. M. Tolbert, and P. F. Yankwich, Isotopic carbon (J. Wiley \& Sons, Inc., New York, N.Y., 1949).

[4] J. Rydberg, Acta Chem. Scand. 12, 399 (1958).

[5] W. B. Mann and H. H. Seliger, Preparation, maintenance, and application of standards of radioactivity, NBS Circ. 594, p. 28 (1958).

[6] A. Schwebel, H. S. Isbell, and J. D. Moyer, J. Research NBS 53, 221 (1954) RP2537.

[7] W. M. Jones, Phys. Rev. 100, 124 (1955).

[8] H. S. Isbell, J. V. Karabinos, H. L. Frush, N. B. Holt, A. Schwebel, and T. T. Galkowski, J. Research NBS 48, 163 (1952) RP2301.

[9] H. S. Isbell, H. L. Frush, and N. B. Holt, J. Research NBS 64A, 135 (1960).

[10] H. S. Isbell and J. D. Moyer, J. Research NBS 63A, 177 (1959).

[11] R. W. Hendler, Science 130, 772 (1959).

[12] M. D. Kamen, Isotopic tracers in biology, 3d edition (Academic Press Inc., New York, N.Y., 1957).

Washington, D.C.

(Paper 64A4-61) 


\section{Publications of the National Bureau of Standards*}

\section{Selected Abstracts}

Non-self-adjoint boundary value problems in ordinary differential equations, W. Greub and W. C. Rheinboldt, J. Research NBS 64B, No. 2, 83 (1960).

It is shown that the theory of non-self-adjoint linear ordinary differential equations can be simplified and unified, if, instead of specifying linear boundary conditions in the conventional way, one merely specifies the linear subspace determined by the boundary conditions. If this is done, the corresponding linear space of the adjoint problem is the orthogonal complement of the original space with respect to the scalar product defined by the right-hand side of Green's boundary formula.

\section{Half-round inductive obstacles in rectangular waveguide,} D. M. Kerns, J. Research NBS 64B, No. 2, 113 (1960).

Formulas are derived for the accurate calculation of the lowestmode, lumped-element representation of perfectly conducting half-round inductive obstacles in rectangular waveguide. These obstacles consist of either one or two opposed semicircular cylindrical indentations extending across the narrow sides of the waveguide. They seem especially suitable for use as precise calculable standards of reflection or impedance in waveguide. Using essentially well-known methods, the desired parameters are expressed as functionals of the unknown obstacle currents, which are determined by integral equations. Explicit formulas are obtained for the values of the parameters under the assumption of $n$-term Fourier sine-series expansions for the obstacle currents; rapid convergence is indicated by numerical evaluations for $n=1,2$, and 3 . In the process of obtaining expressions suitable for numerical calculation, an expansion (believed to be new) of the Green's function of the problem is obtained and the sums of certain infinite series of Bessel's functions occurring in this expansion are expressed in terms of definite integrals. A brief numerical table of these sums, sufficient for the evaluation of the $n=1$ approximation, is included.

Relation of turbulence theory to ionspheric scatter propagation experiments, A. D. Wheelon, J. Research NBS 64D, No. 4 , $301(1960)$.

This paper attempts to relate turbulence theories to radio measurements on VHF ionospheric forward scatter circuits. To this end, the single scattering description of the electromagnetic response of electron density irregularities and the corresponding transmission expression are evaluated. Statistical distributions of signal levels are found to agree with a scattering model. The several theories for turbulent mixing of the electron density are then summarized. A turbulence mixing model is compared favorably with experimental data on absolute signal levels and their diurnal and seasonal variations. Scattering heights in the ionosphere responsible for the signals are also consistent with these theories. Frequency and distance dependence scaling laws are compared briefly with the data. The scatter signal behavior during sudden ionospheric disturbances is also explained. No attempt is made to compare meteoric and turbulence scatter contributions to the measured quantities in this paper. Approximately 30 references are given

Propagation of oblique incidence over cylindrical obstacles, M. P. Bachynski, J. Research NBS 64D, No. 4, 311 (1960).

Investigations of propagation of short electromagnetic waves at oblique incidence over smooth, perfectly conducting cylindrical obstacles are described. It is shown that the effect of oblique incidence can be considered as a change in the effective radius of curvature of the diffracting obstacle. The power in the shadow region of a cylindrical obstacle decreases with angle of obliqueness for horizontally polarized waves and can decrease, remain constant, or increase with angle of obliqueness for vertically polarized waves depending on the geometry of the propagation link. In all cases, vertical polarization gives a stronger field in the shadow region than horizontal polarization. In addition, it is shown that the diffracted field behind an obstruction of uniform radius of curvature is the same as that behind an obstacle of uniformly varying radius of curvature, provided the effective radius is the same.

Diffraction by smooth conical obstacles, H. E. J. Neugebauer and M. P. Bachynski, J. Research NBS 64D, No. 4, 317 (1960)

Expressions obtained earlier for the calculation of diffraction due to conducting obstacles with smooth cylindrical surfaces are generalized to oblique incidence and to surfaces of conical shape. The derivation is based on a generalized concept of the Green's function and on the use of corrective factors that take the same place as corrections introduced by other authors into the theory of diffraction by apertures. The final expressions for conical obstacles and oblique incidence are very similar to those for cylindrical obstacles. The results are compared with scale model measurements.

Mode theory and the propagation of ELF radio waves, J. R. Wait, J. Research NBS 64D, No. 4, 387 (1960).

The mode theory of propagation of electromagnetic waves at extremely-low-frequencies ( 1.0 to $3,000 \mathrm{cps}$ ) is treated in this paper. Starting with the representation of the field as a sum of modes, approximate formulas are presented for the attenuation and phase constants. Certain alternate representations of the individual modes are mentioned. These are used as a basis for describing the physical behavior of the field at large distances from the source, particularly near the antipode of the source. At the shorter distances, where the range is comparable to the wavelength, the sphericalearth mode series is best transformed to a series involving cylindrical wave functions. This latter form is used to evaluate the near field behavior of the various field components. The effect of the earth's magnetic field is also evaluated using a quasi-longitudinal approximation. In general it is indicated that if the gyrofrequency is less than the effective value of the collision frequency, the presence of the earth's magnetic field may be neglected for ELF. When this condition is not met the attenuation may be increased somewhat. The influence of an inhomogeneous ionosphere is also briefly considered and finally, the propagation of ELF pulses are treated. It is suggested that certain observed characteristics of ELF waveforms may be attributed to the inclination of the current channel in the lightning discharge.

Half-wave cylindrical antenna in a dissipative medium: current and impedance, Ronold King and C. W. Harrison, J. Research NBS 64D, No. 4, 365 (1960).

An integral equation for the distribution of current along a cylindrical antenna in a conducting dielectric is derived. It is shown that the boundary conditions for an antenna in such a medium are formally the same as for an antenna in free space. The equation is solved for the current $I$ and the driving-point impedance $Z$ by means of a technique that achieves sufficiently high accuracy in the leading terms of an iteration procedure so that the higher-order terms do not need to be evaluated. Moreover, these leading terms consist only of trigonometric functions with complex coefficients. The electromagnetic field in the infinite dissipative medium may be computed easily and in closed form since the current in the antenna is expressed in such simple terms.

A numerical analysis is made to determine the properties of an antenna with an electrical length of one-half wavelength 
in the medium with conductivity $\sigma$ and relative dielectric constant $\epsilon_{r}$. Universal curves are given of $I / \sqrt{\epsilon_{r}}$ with $\sigma / \omega \epsilon_{0} \epsilon_{r}$ as the parameter and of $Z \sqrt{\epsilon_{r}}$ with $\sigma / \omega \epsilon_{0} \epsilon_{r}$ as the variable in the range $0 \leq \sigma / \omega \epsilon_{\mathrm{o}} \epsilon_{r} \leq 0.4$. A table of numerical values of the impedance is given for media such as an isotropic ionosphere, dry salt, dry earth, wet earth, and lake water.

Quantum-mechanical calculation of the probability of an exchange reaction for constrained linear encounters, J. Mazur and R. J. Rubin, J. Chem. Phys. 31, No. 5, 1395 (1959).

A numerical procedure suitable for use with a high-speed computing machine is developed for calculating the average quantum-mechanical probability of the exchange reaction $\mathrm{BC}+\mathrm{A} \rightarrow \mathrm{B}+\mathrm{CA}$ for constrained linear encounters at temperature $T$ when $\mathrm{BC}$ is initially in its ground or first excited vibrational state. The average refers to the average over the relative momentum frequency distribution of collisions between $\mathrm{BC}$ and $\mathrm{A}$ at temperature $T$. The procedure, which involves the numerical solution of the time-dependent Schrödinger equation, is sufficiently general so that any threeatom potential energy surface may be used. Two sample calculations have been performed using a simple potential energy surface. The results of these quantum-mechanical calculations for the average probability of reaction are compared with the corresponding classical quantities which are obtained in an elementary fashion.

Monte Carlo calculations of gamma ray backscattering, M. J. Berger and D. J. Raso, Radiation Research 12, No. 1, 20 (1960).

Monte Carlo calculations have been performed to determine the backscattering of gamma rays from semi-infinite media (hydrogen, water, concrete, iron, tin, and lead). Radiation with energies of $0.05,0.1,0.2,0.5,1.0$, or $2.0 \mathrm{Mev}$ was assumed to be incident isotropically or at angles of $0^{\circ}$ (perpendicular incidence), $30^{\circ}, 60^{\circ}$, or $90^{\circ}$ (grazing incidence). 5,000 photon histories were followed for each case on an IBM 704 computer. The information obtained includes the number albedo and energy albedo and the energy spectrum and angular distribution of the reflected radiation.

On the diffraction of electromagnetic pulses by curved conducting surfaces, J. R. Wait and A. M. Conda, Can. J. Phys. 37, 1384 (1959).

Starting with the known steady state solutions for diffraction by a perfectly conducting convex surface, the corresponding transient responses are derived using Fourier-Laplace inversion. Explicit results are given for an incident wave which varies with time as a step function.

New wavelengths for some helium $(\mathrm{He}$ I) lines, W. C. Martin, J. Opt. Soc. Am. 50, No. 2, 174 (1960).

New vacuum wavelengths for nine lines of $\mathrm{He}$ I in the near ultraviolet and visible regions are given. They were obtained by measurement relative to $5462.2707 \mathrm{~A}$ and $4359.5625 \mathrm{~A}$ of $\mathrm{H}^{198} \mathrm{I}$ with an evacuated Fabry-Perot interferometer. Liquid-nitrogen cooled helium lamps were used. Interference fringes were obtained for the helium line 5017 A with spacers up to $50 \mathrm{~mm}$ in length. The wavelength of this line, which was used as a reference wavelength in some previous work on the Rydberg constant, is found to be $5017.0772+0.0003 \mathrm{~A}$ (vac.) relative to the stated values for the two standards.

Geomagnetic effects of high-altitude nuclear explosions, A. G. MeNish, J. Geophys. Research 64, No. 12, 2253 (1959).

Two high-altitude nuclear explosions detonated near Johnston Island in August 1958 produced distinct geomagnetic effects at Honolulu, Palmyra Island, Fanning Island, Jarvis Island, and Apia. No other operating magnetic observatories exhibited discernible effects. The effects at the first four observatories are attributed to overhead currents caused by increased ionization of the atmosphere by gamma rays and their secondaries from the detonations. The effects at Apia are attributed to charged particles from the detonations and Compton electrons released from the air around the detonation.
Determination of piezoelectric properties as a function of pressure and temperature, J. E. McKinney and C. S. Bowver, J. Acoust. Soc. Am. 32, No. 1, 56 (1960).

Piezoelectric data on a mixed titanate system $\left(82 \% \mathrm{BaTiO}_{3}\right.$, $9.1 \% \mathrm{CaTiO}_{3}, 3.6 \% \mathrm{PbTiO}_{3}$, and $4.4 \% \mathrm{TiO}_{2}$ ) was obtained from an apparatus intended to measure the dynamic compressibility of materials. The calibration constant of the apparatus involves the piezoelectric and dielectric constants of the ceramics used as transducers. The method is discussed and an operating equation for the apparatus derived. Piezoelectric and dielectric constants have been measured over a fairly extensive temperature and pressure range and an apparent phase transition observed near $5^{\circ} \mathrm{C}$. This transition corresponds to that found in pure barium titanate, and might be due to imperfect mixing of the titanates that leaves a small amount of pure barium titanate present. The method described appears more sensitive for the detection of changes in crystal symmetry in such materials than either X-ray or dielectric measurements.

Line shape and $\boldsymbol{f}$ value in the $\mathrm{OH}{ }^{2} \Sigma^{+}-{ }^{2} \pi$ transition, T. Carrington, J. Chem. Phys. 31, No. 5, 1243 (1959).

Line shape and $f$ value in the ultraviolet transition ${ }^{2} \Sigma^{+}-{ }^{2} \pi$ of $\mathrm{OH}$ have been studied by the curve of growth method, and rough direct measurements of line width have been made. The lines $\mathrm{Q}_{1} 6, \mathrm{P}_{1} 6, \mathrm{R}_{1} 6, \mathrm{Q}_{21} 6$, and $\mathrm{S}_{1} 6$ fit a curve of growth indicating a collision broadening width of $0.02 \pm 0.02$ $\mathrm{cm}^{-1}$ at $2,600^{\circ} \mathrm{K}$ and $1 \mathrm{~atm}$ in flame gases of the approximate composition $\mathrm{O}_{2} 60 \%, \mathrm{H}_{2} \mathrm{O} 20 \%$ and $\mathrm{CO}_{2} 20 \%$. For the $Q_{1} 6$ line, the $f$ value is $(11.7 \pm 3) \times 10^{-4}$. This corresponds to a radiative lifetime for the free molecule of $5.5 \times 10^{-7}$ sec, in excellent agreement with the earlier work of Oldenberg. Brief discussions are given of theoretical limitations on the use of the curve of growth, and of the qualitative factors to be considered in explaining the observed line width.

Experimental and theoretical investigation of the magnetic properties of iron oxide recording tape, E. D. Daniel and I. Levine, J. Acoust. Soc. Am. 32, No. 1, 1 (1960).

Part A gives the results of remanent magnetization tests made under ordinary and anhysteretic conditions, and shows that the major anhysteretic properties of a recording tape can be expressed in terms of three easily measured constants. The design of the test equipment is discussed and test results are listed for 13 representative types of tape. Part B reviews some of the theories of fine particle magnets that can be applied to recording tape, and gives an extensive treatment of remanent magnetization based upon the Preisach diagram. Some aspects of the Preisach diagram treatment may be of interest to workers outside the magnetic recording field The anhysteretic properties are important in hf biased recording and a second paper describes how these properties can be used to predict certain recording performance characteristics.

Determination of the recording performance of a tape from its magnetic properties, E. D. Daniel and I. Levine, J. Acoust. Soc. Am. 32, No. 2, 258 (1960).

This is the second of two papers. The first (I) dealt with the general magnetic properties of recording tape. The present paper gives an analysis of hf-biased recording based upon the amhysteretic properties of the tape as specified in I. Calculations of performance are compared with the results of absolute measurements carried out on a conventional recording machine, and on large scale models. Satisfactory agreement is obtained when the theory is corrected to take into account a loss attributed largely to a dynamic form of demagnetization which takes place during recording. The corrected theory can be used to compare tape performance under a variety of operating conditions without reference to a particular test recorder. Attention is confined to recorded wavelengths which are large compared with coating thickness. 
Departures from the Saha equation under varying conditions of Lyman continuous opacity, S. R. Pottasch and R. N. Thomas, Astrophys. J.130, No. 3, 941 (1959).

A general method for determining the departure from the Saha equation in a hydrogen atmosphere is presented. The usually stated, vague condition of "high opacity in the Lyman continuum" is not sufficient to insure LTE; departures from LTE may amount to several orders of magnitude even under this condition (fig. 2). For illustration, application of the method is made to an atmosphere of constant $T_{e}$ and $n_{e}$ (fig. 1) and to an approximate chromospheric model (fig. 3).

Vibration-rotation bands of ammonia. IV. The stretching fundamentals and associated bands near $3 \nu$, W. S. Benedict, E. K. Plyler, and E. D. Tidwell, J. Chem. Phys. 32, No. 1, $32(1960)$.

High-resolution spectra of $\mathrm{NH}_{3}$, yielding 1,800 lines between $3,060-3,580 \mathrm{~cm}^{-1}$, are presented. Analysis of the $\mu_{3}$ fundamental is complete through $J^{\prime}=9$ and presents no unexpected features. Resolution of the $K$-substructure in the $\nu_{1}$ fundamental shows that several perturbations are present. The most important of these, fnvolving a Fermi resonance with the parallel component on $2 \nu_{4}$, and a Coriolis resonance with its perpendicular componet, are clarified. Lines in both components of $2 \nu_{4}$ are identified through $J^{\prime}=6$, and a strong Coriolis interaction between the $l=0$ and $l=2$ states is observed and discussed.

Electron impact studies of aromatic hydrocarbons, I. Benzene, napthalene, anthracene, and phenanthrene, $M$. E. Wacks and V. H. Dibeler, J. Chem. Phys. 31, No. 6, 155y (1959).

A systematic survey of ionization-dissociation processes of fused-ring aromatic compounds is initiated. Mass spectra and appearance potentials of the singly and doubly charged molecule ions are reported.

The observed ionization potentials of benzene $(9.38 \mathrm{ev})$, naphthalene $(8.26 \mathrm{ev})$, anthracene $(7.55 \mathrm{ev})$, and phenanthrene $(8.03 \mathrm{ev})$ are compared with available spectroseopic data, with values obtained from molecular orbital calculations, and with other electron impact data. The empirical method of group equivalents is extended to the calculation of the ionization potentials of the fused-ring aromatic compounds.

Value of the Rydberg constant, W. C. Martin, Phys. Rev. 116, No. 3, 654 (1959)

The spectroscopic measurements of Houston and of Chu pertinent to the Rydberg constant have been adjusted to a new wavelength value $(5015.6779 \pm 0.0003 \mathrm{~A}$ in air) for the helium line used as a standard by them. This new wavelength, based primarily on recent measurements by the author and by Series and Field, replaces the value $5015.675 \mathrm{~A}$ accepted by Houston and Chu. The adjustment brings their data into good agreement with spectroscopic observations relative to the cadmium primary standard made by Drinkwater, Richardson, and Williams. Cohen's conclusion in 1952 that the disagreement of Houston's and Chu's results with those of Drinkwater, Richardson, and Williams was due to a discrepancy in the two standards is thus verified.

In addition, a reappraisal of the data of Chu and of Drinkwater, Richardson, and Williams has resulted in a treatment of their observations substantially different from that given by Cohen. The value of the Rydberg constant resulting from a weighted averaging of all the data, $R_{\infty}=109737.312$ $+0.008 \mathrm{~cm}^{-1}$, is, however, in excellent agreement with the presently accepted value, $109737.311 \pm 0.012 \mathrm{~cm}^{-1}$, calculated by Cohen from the data of Drinkwater, Richardson, and Williams.

Confidence intervals for the expectation of a Poisson variable, E. L. Crow and R. S. Gardner, Biometrika 46, 441 (1959).

A table of "optimum" two-sided confidence intervals for the mean of a Poisson variable is presented for confidence coeffi- cients $80,90,95,99$, and 99.9 percent and all values of the variable 0 through 300 . The intervals are compared in length with other existing or possible systems of intervals for the Poisson mean. The method of calculation is stated, and an interesting property of Poisson probability sums useful in the calculation is derived.

Electron characteristic energy losses in some intermetallic compounds, B. Gauthe, Phys, Rev. 114, No. 5, 1265 (1959).

Measurements have been made of the characteristic energy losses of 30-kev electrons in transmission through thin films of indium, indium antimonide, cadmium telluride, and zinc telluride; for comparison, the electron energy losses in antimony, cadmium, tellurium, and zinc have been reinvestigated. The energy loss spectra in these intermetallic compounds appear significantly different from a simple superposition or average of the energy loss spectra of the component metals. Some detailed interpretations of the characteristic energy losses in In and in InSb are suggested.

Adsorption, diffusion, and evaporation of carbon monoxide or tungsten, R. Klein, J. Chem. Phys. 31, No. 5, 1306 (1959).

The surface migration, adsorption, and evaporation processes for carbon monoxide on tungsten have been examined with a field emission microscope operating at liquid helium temperature. Surface migration, both in the Van der Waals' laver and the chemisorbed layer, has been investigated. The desorption process is observed both visually and by consideration of the preexponential factor of the Fowler-Nordheim expression for the whole emitting point.

Studies of borate minerals. VI: Veatchite, J. R. Clark, M. E. Morse, A. Perloff, and G. Burley, Am. Mineralogist 44, No. 11-12, 1141 (1959).

Veatchite is a hydrated strontium borate originally described by Switzer (1938). In the present study X-ray precession patterns have been correlated with crystal habit and indices of refraction to yield the following data: monoclinic, space group $A 2 / a-C_{2} h^{6}$ (or less likely, $A a-C_{s}{ }^{4}$ ), $a=20.81 \pm 0.04$, $b=11.74 \pm 0.03, c=6.637 \pm 0.02 \AA, \beta=92^{\circ} 02^{\prime} \pm 05^{\prime}, \quad \mathrm{V}=1620$ $\AA^{3}$; dominant forms $\{100\},\{111\},\{h 11\}$ with $h=2,3,4$; cleavage perfect parallel to $(100)$ and $(011)$; optical orientation $Z=b$, $X=c, Y \wedge a=-2^{\circ}$. Previous chemical analyses considered together with the present ervstallographic data show that the correct formula is $\mathrm{SrO} \cdot 3 \mathrm{~B}_{2} \mathrm{O}_{3} \cdot 2 \mathrm{H}_{2} \mathrm{O}$, one of two possibilities proposed by Switzer and Brannock (1950). For eight [SrO $\left..3 \mathrm{~B}_{2} \mathrm{O}_{2} \cdot 2 \mathrm{H}_{2} \mathrm{O}\right]$ per cell, the calculated density is 2.86 g.cm. ${ }^{-3} ;$ an observed density of $2.78 \pm 0.03$ g.cm. ${ }^{-3}$ was obtained on the Berman balance for a $2.4 \mathrm{mg}$. sample of excellent single crystals. X-ray powder pattern data are given with calculated interplanar spacings for $d \geq 2.300 \mathrm{~A}$

The adhesion of electrodeposited nickel to chromium at elevated temperatures, W. E. Reid, Jr., and F. Ogburn, $J$. Electrochem. Soc. 107, No. 2, 91 (1960).

The use of a composite coating of electrodeposited nickel and chromium to protect molybdenum from oxidation at elevated temperatures has certain practical limitations. Examination of the composite coating showed that the problems of blister formation, weakening of the bond between nickel and chromium, and edge separation were interrelated. Blisted formation was eliminated and edge separation reduced slightly by an improved treatment of the chromium surface prior to nickel plating. The weakening of the bond between nickel and chromium appears to be inherent to the coating system.

Chloride content of the diffusion layer at a silver anode, P. A. Krasley, J. Electrochem. Soc. 10\%, No. 2, 139 (1960).

The depletion of chloride in the diffusion layer of a silver electrode was investigated. A microporous silver electrode was used, and the diffusion layer was drawn off through the pores of the electrode. The maximum reduction of chloride ion obtained was about 80 percent. 
Chemical structure and stability relationships in polymers, $B$. G. Achhammer, M. Tryon, and G. M. Kline, Kunststoffe Combined with German Plastics Digest 49, No. 11, 600 (1959); Modern Plastics 37, No. 4, 131 (1959).

Stability of polymers is usually considered in terms of a material's ability to withstand specified conditions and still retain the physical properties required for use of the material in a given application. Admitting that the retention of desired physical properties is a matter of practical concern, it is necessary to recognize the basic problem in stability of polymers as being degradation of a chemical structure involving environment and available energy. Resultant changes in chemical structure then determine the material's physical properties.

On the convergence of the Rayleigh quotient iteration for the computation of characteristic roots and vectors, VI. (Usual Rayleigh quotient for nonlinear elementary divisors), A. M. Ostrowski, Arch. Rat. Mech. Anal. 4, No. 2, 153 (1959).

In this paper the classical Rayleigh quotient iteration is discussed for eigenvalues with nonlinear elementary divisors. The convergence of the method is only then satisfactory, if it is combined with the accelerating methods of Steffensen and Householder, but in this last case it turns out to be at least as good as the method of the generalized Rayleigh quotient.

The weighted compounding of two independent significance tests, M. Zelen and L. S. Joel, Ann. Math. Stat. 30, No. 4. 885 (1959).

Suppose an experimenter wishes to combine the results of two independent statistical tests made on the same null hypothesis into a single combined test. The tests may have arisen from several sets of independent data or from independent tests made on the same data. Often it is difficult to pool the data from both tests and resort must be made to combining the tests themselves.

The object of this paper is to discuss a proposed test for combining two such independent tests, each based on the variance-ratio or $F$-distribution. A method for combining the two tests is proposed which weights one test relative to the other.

Sauter theory of the photoelectric effect, U. Fano, K. W. MeVoy, and J. R. Albers, Phys. Rev. 116, No. 5, 1147 (1959).

Results of Sauter are expressed in the form of a transition matrix which determines the photoelectric effect cross section for arbitrary X-ray polarization and arbitrary initial and final orientations of the electron spin. The structure of the matrix elements accounts for curious properties of the cross section in terms of interference between orbital and spin currents. Expansion of the wave functions into powers of $Z / 137$ simplifies the calculation of the transition matrix reduces it to a special case of the bremsstrahlung theory in Born approximation, and explains discrepancies between results of earlier calculations. Analytical and graphical data are given on the photoemission of polarized electrons by circularly polarized X-rays.

High-frequency limit of bremsstrahlung in the Sauter approximation, U. Fano, Phys. Rev. 116, No. 5, 1156 (1959).

The expansion in powers of $Z / 137$ utilized in the Sauter theory of the photoelectric effect yields a nonzero cross section proportional to $Z^{3}$ at the high-frequency limit of the bremsstrahlung spectrum, and also at the low electron energy limit of the pair production spectrum. These cross sections are related to the Sauter photoelectric cross section by detailed balancing. The results apply equally when the effects of spin orientations and X-ray polarization are considered.

Interference of orbital and spin currents on bremsstrahlung and photoelectric effect, U. Fano, K. W. McVoy, and J. R. Albers, Phys. Rev. 116, No. 5, 1159 (1959).

The matrix elements of the Born approximation theory of bremsstrahlung are resolved into sums of terms classified according to whether the radiation interacts with orbital or with spin currents and on the basis of additional spin effects which result from electron motion before and after the emission. Observable features of angular distribution, X-ray polarization, and spin orientation can be interpreted as effects of interference between the separate terms. The results are applicable to corresponding features of the photoelectric effect.

Bremsstrahlung and the photoelectric effect as inverse processes, K. W. MeVoy, and U. Fano, Phys. Rev. 116, No. 5, 1168 (1959)

The bremsstrahlung matrix element at the short-wavelength limit of the spectrum is calculated to lowest order in $a \equiv Z / 137$, for an unscreened Coulomb field. The result, valid for relativistic incoming electrons, is shown to be exactly $\alpha^{-1} m^{-1 / 2}$ times the complex conjugate of Sauter's relativistic matrix element for the $K$-shell photoelectric effect. These matrix elements are the leading terms in an expansion of the exact matrix elements in powers of $\alpha$, and they are found to be derivable from the first two terms of the expansions in powers of $\alpha$ of the electron wave functions. In this sense their structure is completely analogous to that of the Bethe-Heitler bremsstrahlung matrix element.

This simple relation between the matrix elements derives from an approximate equality (through first order in $\alpha$ between the Coulomb wave functions for bound and zero-momentum continuum states, which can be understood as due to the neglect of the Coulomb binding energy, a second-order quantity in $\alpha$.

Finally, the range of validity of Sauter's approximation is examined in detail. The lower bound of this (energy) range is found to be simply related to the radius of convergence of the expansion of the photoeffect matrix element in powers of $\alpha$.

Balmer decrements: the diffuse nebulae, S. R. Pottasch, Astrophys. J. 131, No. 1, 202 (1960).

The possibility that diffuse nebulae may have a total optical depth of the order of unity is considered. The Balmer decrement is found as a function of the total optical depth of a plane atmosphere in $H \alpha$, assuming that the atmosphere has a constant temperature and density (less than $10^{5}$ electrons/ $\mathrm{cm}^{3}$ ) and is optically thick to Lyman line radiation. It is found that the $H \alpha / H \beta$ ratio increases with increasing optical depth in $H \alpha$.

The observations of $H \alpha / H \beta$ in diffuse nebulae are high enough as to make any other interpretation beside that of optical thickness in $H \alpha$, appear doubtful.

Fusion of polymer networks formed from linear polyethylene: Effect of intermolecular order, L. Mandelkern, D. E. Roberts, J. C. Halpin, and F. P. Price, J. Am. Chem. Soc. 82, 46 (1960).

Specimens of linear polyethylene have been crosslinked at a variety of temperatures both above and below the melting point by either high energy electrons or by $\mathrm{Co}^{60} \gamma$-rays. The melting points and the specific volume-temperature behavior of these specimens have been examined as functions of radiation dose and irradiation temperature. In general, the two types of radiation give the same results. Both the melting point depression and the reduction in crystallinity are more sensitive to radiation dose when the irradition is carried out above the melting temperature than when it is performed below this temperature. The observed effects are explicable in terms of a recent theory of Flory which envisages that the configurational entropy of an amorphous polymer network is sensitive to the degree of order present when the crosslinks were introduced. These considerations lead to the conclusion that intermolecular order present in a highly crystalline polymer is maintained to some degree in the melt, if the crosslinks are introduced in the crystalline state. Consequently the melting temperatures of networks formed in this manner are significantly higher than those of networks formed when randomly arrayed chains. Furthermore, it was found that the melting temperatures of both types of networks, when immersed in a large excess of liquid, are depressed in accordance with the well-known melting point relation, provided cognizance is taken of the amount of liquid imbibed. 
Electrophoretic deposition of metals, metalloids, and refractory oxides, V. A. Lamb and W. R. Reid, Plating 47, No. 3 , 291 (1960).

Operating conditions are defined for electrophoretically depositing a number of metals, metalloids, and refractory oxides. Conversion of the deposits to practical coatings requires treatments such as chemical reduction and sintering. Further development of the latter steps is necessary before practical coatings can be achieved. Coatings of titaniumnickel alloys on steel may warrant further investigation.

Relative measurement of the photodetachment cross section for $\mathbf{H}^{-}$, S. J. Smith and D. S. Burch, Phys. Rev. 116, No. 5 , $1125(1959)$.

The spectral dependence of the photodetachment cross section for the negative ion of atomic hydrogen has been measured in the range from $4,000 \AA$ to $13,000 \AA$ with approximately $300 \AA$ resolution. Measurements were made with 25 band pass filters, each measurement taken relative to the value obtained with a control filter at 5,280 $\mathrm{A}$. A probable error of about 2 percent is attached to the relative value obtained for each filter. The results are in significant disagreement with available calculated cross sections.

Isotope exchange processes in solid nitrogen under electron bombardment, R. Klein and E. M. Horl, J. Chem. Phys. 3\%, No. 1, 307 (1960).

Investigations were carried out on the isotope exchange in solid nitrogen layers during electron bombardment at $4^{\circ}$ and $20^{\circ} \mathrm{K}$ with mixtures of $\mathrm{N}^{14} \mathrm{~N}^{14}$ and $\mathrm{N}^{15} \mathrm{~N}^{15}$ molecules. The samples were analyzed after bombardment for their $\mathrm{N}^{14} \mathrm{~N}^{15}$ content, and the yield per $100 \mathrm{ev}$ in terms of the number of $\mathrm{N}^{14} \mathrm{~N}^{15}$ molecules produced ( $\mathrm{G}$ value) measured. For undiluted nitrogen at $4.2^{\circ} \mathrm{K}$, a value of the order of 0.2 was obtained. A discussion of the elementary processes involved in the exchange is presented.

Theory of flame propagation in solid nitrogen at low temperatures, S. G. Reed and C. M. Herzfeld, J. Chem. Phys. 32, No. 1, 1 (1960).

A theory for a flame in a solid whose speed is controlled by diffusion of radicals and heat is applied to slowly propagating flashes observed in solid nitrogen deposited at $4^{\circ} \mathrm{K}$ from a microwave discharge. Reasonable agreement is obtained with observed speeds.

Use of the equation of hydrostatic equilibrium in determining the temperature distribution in the outer solar atmosphere, S. R. Pottasch, Astrophys. J. 131, No. 1, 68 (1960).

The temperature distribution from $1.0043(3,000 \mathrm{~km})$ to 20 solar radii in the sun's atmosphere is computed from the observed density distribution in this region and the assumption of hydrostatic equilibrium. The temperature distribution shows a maximum between 1.1 and 3 solar radii and a decrease in temperature thereafter. This decrease in temperature is consistent with Chapman's suggestion of thermal conduction only if loss of energy by radiation is included. Inclusion of a radiative energy loss also is shown to invalidate Parker's argument against hydrostatic equilibrium out to large distances from the sun.

Apparent temperatures measured at melting points of some metal oxides in a solar furnace, J. J. Diamond and S. J. Schneider, J. Am. Ceram. Soc. 43, No. 1, 1 (1960).

Six metal oxides $\left(\mathrm{Al}_{2} \mathrm{O}_{3}, \quad \mathrm{TiO}_{2}, \mathrm{Nb}_{2} \mathrm{O}_{5}, \mathrm{Ta}_{2} \mathrm{O}_{5}, \mathrm{La}_{2} \mathrm{O}_{3}\right.$ and $\mathrm{Dy}_{2} \mathrm{O}_{3}$ ) were melted in a solar furnace and the apparent temperatures at their melting points measured by means of a conventional optical pyrometer. The apparent temperatures of three of them $\left(\mathrm{Al}_{2} \mathrm{O}_{3}, \mathrm{TiO}_{2}\right.$ and $\left.\mathrm{Nb}_{2} \mathrm{O}_{5}\right)$ were $2,025^{\circ}$, $1,840^{\circ}$, and $1,497^{\circ} \mathrm{C}$, respectively, in close agreement with the melting points as determined by other investigators using other methods. The apparent temperatures of the other three varied widely and bore no relation to their melting points. The method does not, therefore, have general utility for the measurement of unknown melting points.
Perovskite-type compounds in binary rare earth oxide systems, S. J. Schneider and R. S. Roth, J. Am. Ceram. Soc. 43, No. 2, 115 (1960).

A survey was made of the solid state reactions that occur in equi-molar mixtures of oxides of the trivalent rare earth ions. It was determined that a perovskite-type compound of the form $\mathrm{A}^{+3} \mathrm{~B}^{+3} \mathrm{O}_{3}$ occurred as a stable phase only in the following binaries: $\mathrm{La}_{2} \mathrm{O}_{3}=\mathrm{Er}_{2} \mathrm{O}_{3}, \mathrm{La}_{2} \mathrm{O}_{3}=\mathrm{Tm}_{2} \mathrm{O}_{3}, \mathrm{La}_{2} \mathrm{O}_{3}=\mathrm{UYb}_{2} \mathrm{O}_{3}$ and $\mathrm{La}_{2} \mathrm{O}_{3}=\mathrm{Lu}_{2} \mathrm{O}_{3}$. A correlation between compound formation and tolerance factor was made.

Use of disodium $m$-benzenedisulfonate as a hardening agent in Watts nickel bath, W. H. Metzger, P. A. Krasley, and F. Ogburn, Plating 47, No. 3, 285 (1960).

A request from the Bureau of Engraving and Printing for an electrodeposit of nickel that was harder and more free of stress than those currently obtained from a Watts bath operated at $5 \mathrm{amp} / \mathrm{dm}^{2}, 50^{\circ} \mathrm{C}$, and $p \mathrm{H} 5.0$ resulted in a recommendation for the use of disodium $m$-benzene-disulfonate as an addition agent. The electrodeposits made in the presence of this agent had the physical properties required by BEP for their new printing plates, while production conditions remained the same. The agent increases deposit hardness to a maximum of $350 \mathrm{VHN}$ at a concentration of $0.3 \mathrm{~g} / \mathrm{l}$ and above, under the operating conditions stated. The stress varies from 20,000 psi tensile to 5,000 psi compressive over a range of concentration of the additive from zero to $0.4 \mathrm{~g} / 1$. This agent causes hardness to vary inversely with $p \mathrm{H}$ in the range studied $(p H$ 4.0-5.0). The relative stability of the agent appears unaffected by conventional purification procedures. Intercomparisons with two spiral contractometers and four coils show that, within the 10 percent experimental error, significant variations can be accounted for in the surface condition of the coils, the "stop-off" procedure inside the coil, and the mechanical differences between individual contractometers.

Some evidence for structural anomalies in pure cristobalite, R. F. Walker, S. J. Schneider, and R. S. Roth, J. Am. Ceram. Soc. 42, No. 12, 642 (1959).

Some evidence is produced for the occurrence of structural anomalies in cristobalite of at least 99.998 percent purity. The anomalies were observed only in samples subjected to heat-treatment over a limited temperature range. In somewhat less pure material (about 99.8 percent) the anomalies could be detected in samples treated over a wider range of temperature. There appeared to be a definite connection between the structural anomalies and the "multiple peak" phenomenon encountered during differential thermal analysis of the samples. Some of the difficulties in attempting to rationalize the observations in terms of the cristobalitetridymite relationships are discussed.

\section{Other NBS Publications}

Journal of Research, Section 64B, No. 2, April-June 1960 75 cents.

Non-self-adjoint boundary value problems in ordinary differential equations. Werner Greub and Werner C. Rheinboldt. (See above abstract.)

Criteria for the existence and equioscillation of best Tchebycheff approximations. John R. Rice.

Note on the solution of Riccati's differential equation. $\mathrm{H}$ Herbert Howe.

On a generalization of the index notation for absolute tensors of arbitrary order. Edmund H. Brown.

Upper and lower bounds for the center of flexure. Lawrence E. Payne.

Half-round inductive obstacles in rectangular waveguide. D. M. Kerns. (See above abstract.)

Journal of Research, Section 64D, No. 4, July-August 1960. 70 cents.

Relation of turbulence theory to ionospheric scatter propagation experiments. Albert D. Wheelon. (See above abstract.) Propagation at oblique incidence over cylindrical obstacles. M. P. Bachynski. (See above abstract.) 
Diffraction by smooth conical obstacles. H. E. J. Neugebauer and M. P. Bachynski. (See above abstract.)

Characteristics of 488 megacycles per second radio signal reflected from the moon. B. C. Blevis and J. H. Chapman.

The use of polarization fading of satellite signals to study the electron content and irregularities in the ionosphere. C. Gordon Little and Robert S. Lawrence.

Note on a test of the equivalence theorem for sporadic $E$ propagation. J. W. Wright and T. N. Gautier.

Davtime attenuation rates in the very low frequency band using atmospherics. W. L. Taylor.

Measured electrical properties of snow and glacial ice. A. D. Watt and E. L. Maxwell.

Some extremely low frequency phenomena. E. T. Pierce.

Mode theory and the propagation of extremely low frequency radio waves. James R. Wait. (See above abstract.)

Studies of natural electric and magnetic fields. G. D. Garland and T. F. Webster.

Natural electromagnetic energy in frequencies below slow tail sferios band. Wallace H. Campbell.

Possible application of the system loss concept at extremely low frequencies. Kenneth A. Norton.

Measurements of the spectrum of radio noise from 50 to 100 cycles per second. M. Balser and C. A. Wagner.

Half-wave cylindrical antenna in a dissipative medium: current and impedance. Ronold King and Charles W. Harrison. (See above abstract.)

Standard X-ray diffraction powder patterns, H. E. Swanson, M. I. Cook, T. Isaacs, and E. H. Evans, NBS Circ. 539, Vol. 10 (1960) 40 cents.

Properties of high-temperature ceramics and cermetsElasticity and density at room temperature, S. M. Lang, NBS Monograph 6 (1960) 20 cents.

Precise measurement of heat of combustion with a bomb calorimeter, R. S. Jessup, NBS Monograph 7 (1960) 25 cents.

Conductive flooring for hospital operating rooms, T. H. Boone, F. L. Hermach, E. H. MacArthur, and R. C. MeAuliff, NBS Monograph 11 (1960) 20 cents.

Tabulation of data on receiving tubes, C. P. Marsden, W. J. Keery, and J. K. Moffitt, NBS Handb. 68 (1959) \$1.00.

Survey of Central Radio Propagation Laboratory research in tropospheric propagation 1948-1956, J. W. Herbstreit and P. L. Rice, NBS Tech. Note 26 (PB151385) (1959) $\$ 4.00$.

Distribution of incoming lettermail at the Baltimore, Maryland City Post Office, B. M. Levin and A. E. Newman, NBS Tech. Note 33 (PB151392) (1959) \$2.50.

A multiplet table of astrophysical interest, C. E. Moore, NBS Tech. Note 36 (PB151395) (1959) \$4.00.

Application of RF micropotentiometers for calibration of signal generators to $1,000 \mathrm{Mc}, \mathrm{L}$. F. Behrent, NBS Tech. Note 37 (PB151396) (1960) 50 cents.

Design and construction of a liquid hydrogen temperature refrigeration system, D. B. Chelton, J. W. Dean, and B. W. Birmingham, NBS Tech. Note 38 (PB151397) (1960) 75 cents.

Helium refrigeration and liquefaction using a liquid hydrogen refrigerator for precooling, D. B. Chelton, J. W. Dean, and T. R. Strobridge, NBS Tech. Note 39 (PB151398) (1960) 50 cents.

Mean electron density variations of the quiet ionosphere IMarch 1959, J. W. Wright and L. A. Fine, NBS Tech. Note 40-1 (PB151399-1) (1960) \$1.25.

Mean electron density variations of the quiet ionosphere 2 April 1959, J. W. Wright and L. A. Fine, NBS Tech. Note 40-2 (PB151399-2) (1960) \$1.25.

Expendable modules as bases for disposal-at-failure maintenance, R. O. Stone, P. Meissner, and K. M. Schwarz, NBS NBS Tech. Note 41 (PB151400) (1960) \$2.25.

Identification of textile coatings by infrared spectroscopy, F. H. Forziati, R. T. Hite, and M. K. Wharton, Am. Dyestuff Reptr. 49, No. 4, 29 (1960).
Propagation and production of electromagnetic waves in a plasma, R. Gallet, Nuovo Cimento Suppl. 13, No. 1, 234 (1959).

Fading rate recorder for propagation research, J. W. Koch, W. B. Harding, and R. J. Jansen, Electronics 32, No. 51, $78(1959)$

Matrix algebra for calculating multicomponent mixtures, F. Ordway, Portland Cement Assoc. J. Research and Develop. Labs. 2, No. 1, 28 (1960).

Leonard Euler's integral: A historical profile of the gamma function, P. J. Davis, Am. Math. Mo. 66, 849 (1959).

Gages for measuring the thickness of chromium on the internal surface of small-bore tubes, V. A. Lamb and P. A. Krasley, Plating 47, No. 2, 176 (1960).

Characteristics of deposits, W. H. Metzger, Jr. Symp. Electroless Nickel Plating, ASTM Spec. Tech. Pub. 265, p. 13 (1959). Turbulent motion, G. B. Schubauer and C. M. Tchen, Sec. B, Vol. V, Princeton Ser., High speed aerodynamics and jet propulsion, Turbulent flows and heat transfer, p. 75 (Princeton Univ. Press, Princeton, N.J., 1959).

Efficient harmonic generation, G. F. Montgomery, Proc. IRE 48, No. 2, 251 (1960).

The ninth plenary assembly of the CCIR, J. W. Herbstreit, IRE Proc. 48, 45 (1960).

Effect of fluorides on infrared transmittance of certain silicate glasses, G. W. Cleek and T. S. Scuderi, J. Am. Ceram. Soc. 42, No. 12, 599 (1959).

Condltions at the ionization and shock fronts in collisions of gas clouds-Bright rims in diffuse nebulae, pt. VI, S. R Pottasch, Rev. Modern Phys. 30, No. 3, 1053 (1958).

Spectral emittance of ceramic-coated and uncoated specimens of Inconel and stainless steel, J. C. Richmond and J. E. Stewart, J. Am. Ceram. Soc. 42, No. 12, 633 (1959).

Mismatch errors in cascade-connected variable attenuators, G. E. Schafer and A. Y. Rumfelt, IRE Trans. Microw. Theory Tech. MTT- 7 , No. 4, 447 (1959).

A study of 17-7 PH stainless steel, N. L. Carwile and S. J. Rosenberg, WADC Tech. Rept. 58-653 (1959) (available from the Office of Technical Services, Department of Commerce, Washington 25, D.C.).

High-altitude observation techniques, D. M. Gates, Letter Sci. 131, 266 (1960).

The relation between confidence intervals and tests of significance a teaching aid, M. G. Natrella, Am. Stat. 14, No. 1, 20 (1960).

The effect of the earth's magnetic field on m.u.f. calculations, K. Davies, J. Atmospheric and Terrest. Phys. 16, 187 (1959).

Surface area and exchange capacity relation in a Florida kaolinite, W. C. Ormsby and J. M. Shartsis, J. Am. Ceram. Soc. 43, No. 1, 44 (1960).

Standard frequency transmission and time signals, W. D George, Proc. 2d all-IRIG Symp., prepared by Secretariat, Inter-Range Instrumentation Group, Oct. 1958 (White Sands Missile Range, New Mexico) p. 141, IRIG Document No. 107-58 (1959).

Atomistic approach to the rheology of sand-water and claywater mixtures, W. A. Weyl and W. C. Ormsby, Ch. 7, Vol. III Rheology-Theory and applications, Ed. by F. R. Eirich, p. 249 (Academic Press, New York, N.Y., 1960).

Diffusion of particles in turbulent flow, C. M. Tchen, Adv. Geophys. 6: Atmospheric diffusion and air pollution, p. 165, Proc. Symp. Oxford, England, Aug. 1958 (Academic Press Inc., New York, N.Y., 1959).

Atmospheric tides and ionospheric electrodynamics, M. L. White, J. Geophys. Research 65, 153 (1960).

LaRecherche sur les radicaux libres au National Bureau of Standards, H. P. Broida, J. chim. phys. 56, No. 2392, $813(1959)$

Are life testing procedures robust? M. Zelen and M. C. Dannemiller, Proc. 6th Natl. Symp. Reliability and Quality Control in Electron. Jan. 11-13, 1960, Inst. Radio Engrs. Inc., p. 185 (1960).

Reception of space diversity transmitters, J. W. Koch, Wireless World (England) 65, No. 10, 512 (1959).

Improved NBS abrasive jet method for measuring abrasion resistance of coatings, A. G. Roberts, ASTM Bull. No. 244, 48 (TP52) (1960). 
Flame-spread measurements by the radiant panel flamespread method, D. Gross, Forest Products J. X, No. 1, $33(1960)$.

Réactions en chaine de radicaux gelés, J. L. Jackson, J. chim. phys. 56, No. 2392, 771 (1959).

Etude spectroscopique des produits de la decharge électrique dan L'Azote condensés a l'état solide à très basse temperature, prevues en faveur de l'existence d'Azote triatomique dans le solide, M. Peyron, E. M. Horl, H. W. Brown, and H. P. Brodia, J. chim. phys. 56, No. 2392, 736 (1959).

What price accurate test methods? A. T. McPherson, ASTM Bull. (ACR Notes Column) No. 244, 7 (1960).

An analysis of time variations in tropospheric refractive index and apparent radio path length, M. C. Thompson, H. B. Janes, and A. W. Kirkpatrick, J. Geophys. Research 65, 193 (1960).

Neutron detection by reactions induced in scintillators, C. O. Muehlhause, pt. I, Fast Neutron Physics, sec. III. B, p. 387 (Interscience Pub., New York, N.Y., 1960).

A relationship between the lower ionosphere and the [OI] 5577 nightglow emission, J. W. McCaulley and W. S. Hough, J. Geophys. Research 64, No. 12, 2307 (1959).
Many changes reflected in new dry cell standard, W. J. Hamer, Mag. of Standards 31, No. 3, 81 (1960).

Etude aux infrarouges de certains solides condensés à partir de decharges en phase gazeuse, K. B. Harvey and H. W. Brown, J. Chim. Phys. 56, No. 2392, 745 (1959).

Water penetration testing machine for sole leather, T. J. Carter, J. Am. Leather Chemists, Assoc. LV, No. 3, 139 (1960).

A note regarding the mechanism of UHF propagation beyond the horizon, A. D. Watt, E. F. Florman, and R. W. Plush, Letter Proc. IRE 48, 252 (1960).

A model of the $\mathrm{F}$ region above $h_{\max } \mathrm{F} 2, \mathrm{~J}$. W. Wright, J. Geophys. Research 65, 185 (1960).

Interference of antioxidant in the determination of low polymer in SBR synthetic rubber, L. T. Milliken and F. J. Linnig, J. Polymer Sci. XLI, No. 138, 544 (1959).

*Publications for which a price is indicated (except for NBS Technical Notes) are available only from the Superintendent of Documents, US Government Printing Office, Washington 25, D.C. (foreion postage, one-fourth additional). Technical Notes are available only from the Office of Technical Services, U.S. Department of Notes are available only from the Office of Technical Services, U. S. Department of journals and the NBS Journal of Research may often be obtained directly from the authors. 